UCRL-JC-117859

PREPRINT

\title{
Low-Cost Packaging of High-Performance Optoelectronic Components
}

\author{
Mark Lowry, Shin-Yee Lu, Mike Pocha and Oliver T. Strand \\ Lawrence Livermore National Laboratory \\ P.O. Box 808 \\ Livermore, CA 94550
}

\section{Prepared for Submittal to}

SPIE

July 24-29, 1994, San Diego, CA

\section{August 1994}

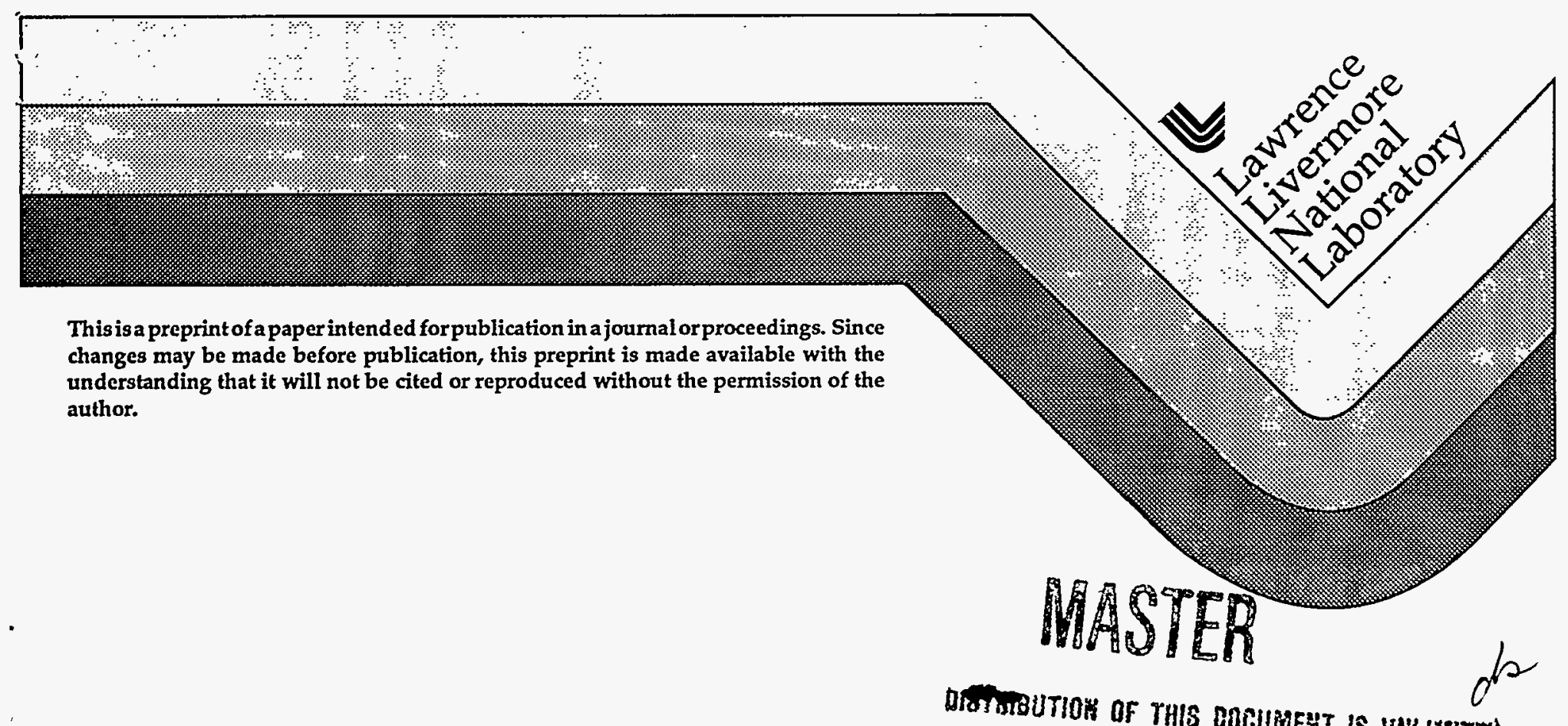

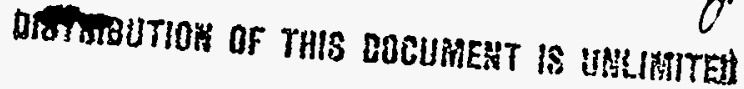




\section{DISCLAIMER}

This report was prepared as an account of work sponsored by an agency of the United States Government. Neither the United States Government nor any agency thereof, nor any of their employees, make any warranty, express or implied, or assumes any legal liability or responsibility for the accuracy, completeness, or usefulness of any information, apparatus, product, or process disclosed, or represents that its use would not infringe privately owned rights. Reference herein to any specific commercial product, process, or service by trade name, trademark, manufacturer, or otherwise does not necessarily constitute or imply its endorsement, recommendation, or favoring by the United States Government or any agency thereof. The views and opinions of authors expressed herein do not necessarily state or reflect those of the United States Government or any agency thereof. 


\section{DISCLAIMER}

\section{Portions of this document may be illegible in electronic image products. Images are produced from the best available original document.}




\title{
Low-Cost Packaging of High-Performance Optoclectronic Components
}

\author{
Mark Lowry, Shin-Yee Lu, Mike Pocha, and Oliver T. Strand \\ Lawrence Livermore National Laboratory
}

\begin{abstract}
Optoelectronic component costs are often dominated by the costs of attaching fiber optic pigtails--especially for the case of single transverse mode devices. We present early results of our program in low-cost packaging. We are employing machine-vision controlled automated positioning and silicon microbench technology to reduce the costs of optoelectronic components.

Our machine vision approach to automated positioning has already attained a positional accuracy of less than 5 microns in less than 5 minutes; accuracies and times are expected to improve significantly as the development progresses.

Complementing the machine vision assembly is our manufacturable approach to silicon microbench technology. We will describe our silicon microbench optoelectronic device packages that incorporate built-in heaters for solder bonding reflow.
\end{abstract}

\section{Introduction}

Optoelectronics (o/e) is currently too expensive for wide-spread application. The packaging (or fiber pigtailing) of o/e components may comprise up to $90 \%$ of the component's cost for some high performance components. The development of an automated packaging system can greatly lower these packaging costs, enabling a host of new applications in areas of great economic and defense benefit to the US, including: optical computer interconnects for advanced computing and ATM switch backplanes; advanced optical networks; and fiber optic gyros to name just a few potentially high-impact applications.

The fundamental reason for the high cost of optoelectronic packaging can be traced to the sub-micron positional tolerances that are usually required for the packaging (or fiber optic pigtailing) of high-performance optoelectronic components. We will briefly discuss below two approachs that we are pursuing at LLNL that can help to minimize these costs.

Automated Optoelectronic Packaging
Automation of the precision positioning may help reduce the costs of optoelectronic components. In an attempt to quantitatively analyze what might be a tolerable cost of such an automated positioning machine and what an economically sensible market volume might be, we have developed a simple model that relates the cost per pigtail to the volume of components that are packaged.

In our model, the per pigtail cost is given by $\mathrm{C}=\left(\mathrm{C}_{\mathrm{op}}(\mathrm{r} / \mathrm{R})+\mathrm{C}_{\mathrm{eq}}\right) / \mathrm{r}+$ $\mathrm{C}_{\text {mat }}$ where $\mathrm{C}_{\text {eq }}$ is the cost per unit time of the machine (we assume that it has a 5 year lifetime), $\mathrm{C}_{\text {mat }}$ is the material costs for each packaged device, $\mathrm{C}_{\text {op }}$ is the cost per unit time of the person operating the machine, $r$ is the market demanded production rate, and $\mathrm{R}$ $=$ machine limited rate of production. These equations are plotted in Fig. 1 for various values of the parameters. Note that as the speed of the machine goes up (time per pigtail decreases) high volume packaging becomes very inexpensive, as one might expect.

It is further interesting to note that as the machine cost goes down, money is saved by automating at lower volumes. Thus a low'-cost machine will provide the economic drive for 
automation at surprisingly small market volumes.

As can be seen in fig. 1 , o/e packaging using this automated machine is expected to be cheaper than manual packaging at pigtail volumes just over 100 per year. This volume would appear to be well within the present market reach of most o/e manufacturers including small companies. Note that as the time per pigtail decreases, the cost decreases greatly at high volumes.

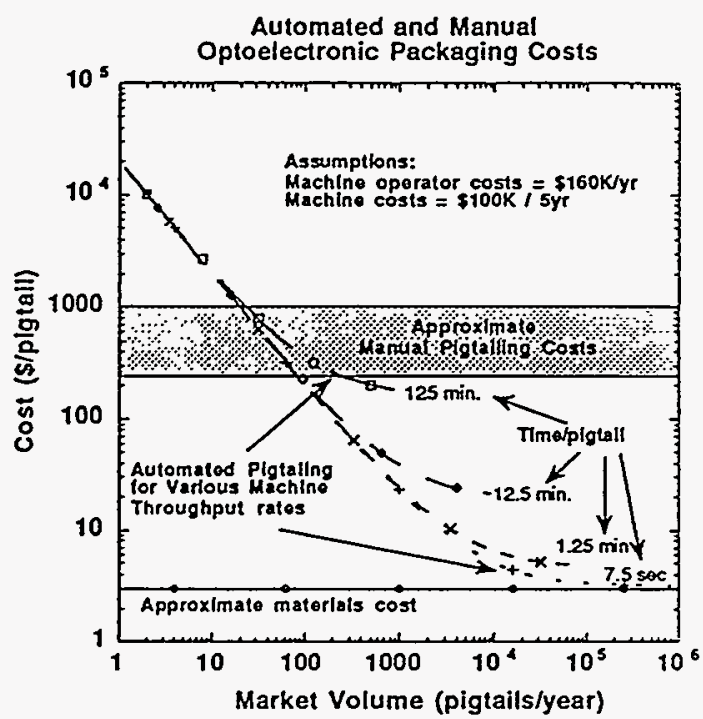

Figure 1. Results of packaging cost model.

Our approach to automation relies heavily on the use of microscopic binocular machine vision. By fabricating optoelectronic devices with fiducials positioned

photolithographically and therefore precisely with respect to the optical waveguide of the device, we are able to use these fiducials to locate the optical waveguides in space. Our binocular machine vision can identify the fiducial and its location and orientation. The computer software then predicts a location for the optical waveguide and its intersection with the substrate edge. A similar machine vision subroutine then locates the optical fiber and calculates the position and orientation of the fiber core. With the two elements successfully located in space, control software directs micropositioners to move the fiber to the waveguide of the optoelectronic device. This process is iterated several times until the waveguide and fiber are within several microns of each other. We dubbed this the machine an Automated Fiber Pigtailing Machine (AFPM). It is diagrammed in Figure 2 below. In this design the two camera that furnish the binocular vision are orthogonal. We have currently successfully demonstrated this system on proton-exchanged lithium niobate waveguides.

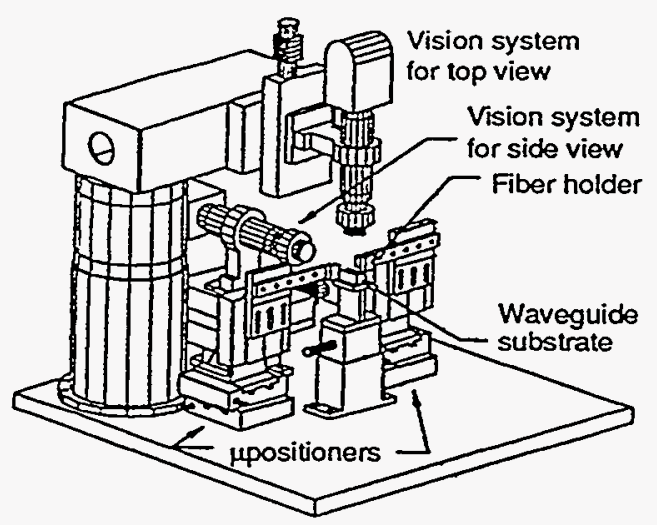

Figure 2. CAD drawing of the AFPM

The software that controls the AFPM and analyzes the camera images is presently in C-language on a 486based PC; we are planning to make the software compatible with a Macintosh, also. The views of the top and side $C C D$ cameras are recorded by a framegrabber with $480 \times 640$ pixels which provides approximately 800 micron fields-of-view with 1.44 micron resolution. Both cameras are mounted on translation stages to provide automatic zoom and focus as well as to view different areas on the modulator; in addition, the top camera is mounted on a rotary stage to move that camera out of the way for the application of epoxy to attach the fibers. The stages that position the fibers are Newport/Klinger PM500 with $25 \mathrm{~mm}$ of travel and 0.05 micron resolution. These stages have sufficient travel and sufficient resolution to satisfy the requirements for both the coarse and fine 
alignment procedures. At present, the computer takes approximately 10 seconds to acquire and analyze the images from the cameras; the subsequent coarse alignment motion of the stages takes less than 1 second. Generally, 6 to 10 images are needed to move the fiber from outside the camera field of view to within a few microns of the modulator waveguide. This means that the coarse alignment takes one to two minutes. The fine alignment of maximizing the amount of light passing between the components uses the patented AutoAlign "hill-climbing" algorithms developed by Newport/Klinger. This procedure also takes one to two minutes for a total time to perform sub-micron alignments of less than five minutes. Future hardware and software upgrades should reduce this time by nearly an order of magnitude.

\section{Silicon Microbenchs with Manufacturable Solder Reflow}

There is a large body of literature on the exploitation of the etching properties of Si to produce v-grooves mesas, and positional stops on silicon substrates to "passively" align optical components. Much work has also been done exploring the use of "solder bumps" to precisely position components in a passive sense. In the interests of space, we make no attempt to review that large body of work, rather we briefly describe what we believe to be an interesting adjunct to these two important packaging technologies.

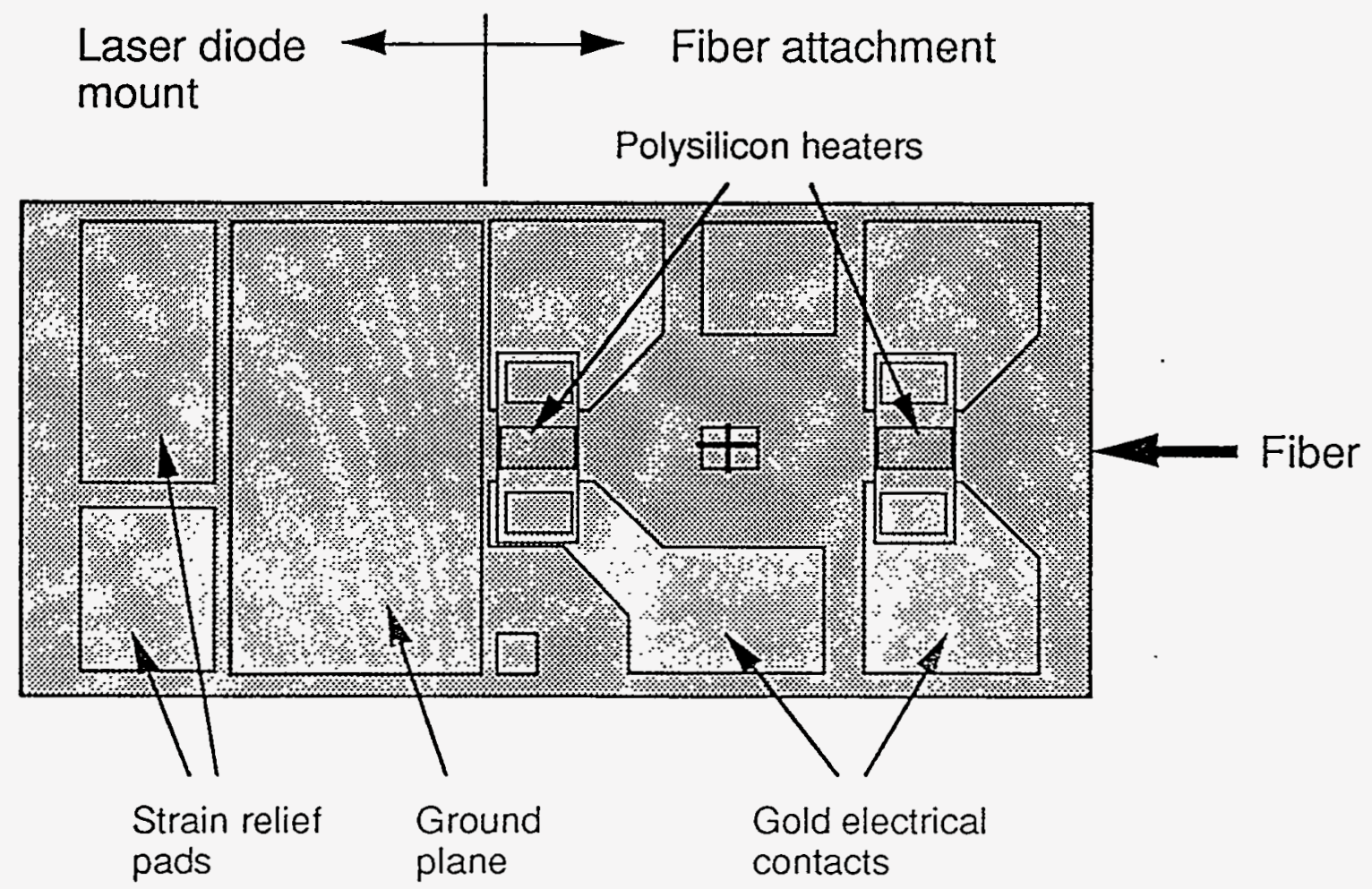

Figure 3. Silicon microbench with built-in polysilicon heaters for manufacturable solder reflow.

We have developed silicon microbenchs with on-board polysilicon heaters to improve the manufacturability of soldered silicon microbenchs. Our initial work involved the development of silicon microbenches to pigtail highpowered $800 \mathrm{~nm}$ laser diodes to single- mode fibers. These microbenches are 13 $\mathrm{mm}$ long by $6 \mathrm{~mm}$ wide and $0.5 \mathrm{~mm}$ thick. The success of the prototype has led us to develop several new designs. For example, the microbench shown in figure 3 is for packaging a $1550 \mathrm{~mm}$ DFB laser. On the left side of the 
microbench, we photolithographically pattern gold pads to provide a ground plane for the laser and stress relief for the wire bonds. To attach the fiber on the other side of the microbench, we build two heating elements of polysilicon which are attached to gold bonding pads for electrical contact. In the center of each heater, we pattern a gold pad on a layer of silicon dioxide. This gold pad provides the solder attachment base while the silicon dioxide electrically isolates the gold pad from the polysilicon heater. The gold pads are $1 \mathrm{~mm}$ by $0.5 \mathrm{~mm}$ each and are sufficiently large to solder a 250 micron diameter fiber at the two attachment pads. Presently, we use either 100micron diameter solder balls or solder paste to attach the metalized fiber. The performance of the polysilicon heaters on our prototype is very reproducible with a specially constructed power supply that allows us to accurately control the magnitude and time of the applied current. Fiber positioning is done by active alignment to sub-micrometer tolerances. While the fiber is held in the position that achieves maximum optical coupling, solder is reflowed to "lock" the fiber in place. We typically apply one amp of current for approximately $0.5 \mathrm{sec}$ to reflow solder at the fiber attachment points. We observe no decrease in the light coupled from an $800 \mathrm{~nm}$ laser diode into a single-mode fiber before and after the solder reflow and cooling, and have achieved upto $65 \%$ optical coupling with conically tapered fibers

Our microbench geometries with on-board heaters allow rapid attachment of not only the fiber but alșo other components to be placed on the microbench. Applying larger currents for longer periods of time allows solder reflow at other locations on the microbench. Using solders with different melting temperatures and judiciously choosing the order of attachment allows a variety of components to be soldered to the microbench without movement of previously attached components. Generally, components furthest from a heater are attached first using a high current through the heater. We can solder a thermoelectric cooler, a thermistor, and a laser diode onto our microbench at different distances from the heaters in less than 15 minutes. The placement of these components does not require sub-micron alignment, and can therefore be done using standard techniques found in the electronics industry, which is heavily automated. We envision that the placement and soldering of these components onto the microbenches could be performed by an automated system in only a few minutes. As the last step, the fiber must be aligned to sub-micron tolerances and is attached using the least current through the heaters.

The idea of on-board heaters lends itself to applications other than packaging laser diodes. We are presently designing a longer microbench with heaters at each end to pigtail both ends of a semiconductor optical amplifier. We are also investigating geometries compatible with high speed applications in which on-board transmission lines will be needed to provide sufficient bandwidth.

\section{Conclusions and Future Work}

We have described some of the ongoing efforts at LLNL to reduce the costs of optoelectronic packaging. As a national laboratory, an increasingly significant portion of our mission is devoted to assisting US industry. We believe the efforts described here are important to the US optoelectronics industry and we are prepared to develop these technologies in partnership with US industry.

We have recently embarked on an ARPA funded program that will build on the automated packaging work descrited here. ARPA will fund LLNL, the MIT Manulacturing Institute, United Techiis avies Photonics, Ortel, and Neuprerlinger to develop a 
commercially available automated optoelectronic packaging machine. The partners in this effort will be reporting on our results in the near future.

\section{Additional Information}

US companies may obtain additional technical information or information on partnering opportunities by contacting any of the following--

$\begin{array}{ll}\text { Contact: } & \text { Ted Strand } \\ \text { Tel.No.: } & (510) 423-2062 \\ \text { FaxNo.: } & (510) 422-1066 \\ \text { Mail Code: } & \text { L-45 } \\ \text { e-mail: } & \text { strandl@llnl.gov } \\ & \\ \text { Contact: } & \text { Shin-yee Lu } \\ \text { Tel.No.: } & (510) 422-6882 \\ \text { FaxNo.: } & (510) 422-3013 \\ \text { Mail Code: } & \text { L-156 } \\ \text { e-mail: } & \text { lu@elm.llnl.gov } \\ & \\ \text { Contact: } & \text { MarkLowry } \\ \text { Tel.No.: } & (510) 423-2924 \\ \text { FaxNo.: } & (510) 422-1066 \\ \text { Mail Code: } & \text { L-45 } \\ \text { e-mail: } & \text { mlowry@llnl.gov } \\ & \\ \text { Contact: } & \text { Mike Pocha } \\ \text { Tel.No.: } & \text { (510) 422-8664 } \\ \text { FaxNo.: } & (510) 422-2783 \\ \text { Mail Code: } & \text { L-222 } \\ \text { e-mail: } & \text { pocha@llnl.gov }\end{array}$

\section{Acknowledgements}

Don Bossi of United Technology

Photonics has provided useful discussions during the development of the cost model presented here. This work was pertormed under the auspices of the U.S. Department of Energy under contract W-7405-ENG-48

at Lawrence Livermore Nationa1 Labortory . 